\title{
How Counselors Play a Role in Psychological Intervention in the New Period
}

\author{
Chao Wang ${ }^{1, a}$ and Junzheng Wang ${ }^{1, b^{*}}$ \\ ${ }^{1}$ Xincheng Street 2888, Jilin Agricultural University, Changchun, Jilin Province 130118, PR China

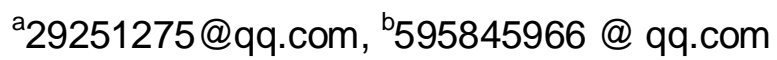 \\ *the corresponding author
}

Keywords: Counselor; Psychological intervention; Way

\begin{abstract}
In today's world, the society change rapidly. College students are facing increasing pressures and challenges, the psychological state of college students are more easily influenced by complex factors, easy to produce psychological crisis. Counselors and college students have more contact. So the instructor shoulders the heavy responsibility of psychological intervention for college students. This paper discusses how the counselors play an important role in the process of psychological intervention in the new period.
\end{abstract}

\section{Psychological Crisis of College Students and Its Inducing Factors}

College Students' Psychological Crisis and Psychological Crisis Intervention. The psychological crisis of college students mainly refers to the university students encounter ordinary coping style can not handle the problem, because can not overcome psychological conflict or stimulation, so resulting crisis.

College Students' psychological crisis intervention refers to using the theory and technology of psychology, psychological counseling, mental health education and other aspects, to have a purpose and a plan, a full range of psychological guidance, psychological counseling or psychological counseling in psychological crisis situations, to help to adjust the serious imbalance of mental state, reduce of the conflict the act, reduce or eliminate the harm that may arise.

The Inducing Factors of Psychological Crisis of College Students. The psychological crisis of college students has a lot of inducing factors, summed up in the following aspects:

A heavy blow in the life of College Students: such as school punishment, parents divorced, houses destroyed and so on.

College students interpersonal barriers: if some students that just entered the university do not adapt to the new environment, they began to become unwilling to interact with people. Some students maybe quarrel with others because of some trivial, or even strike violently.

College students learning difficulties: such as in the study for some time, found their own professional is not as they imagined, and gradually have the weariness psychology to the professional course of study. Again, in the learning process, found that they do not understand the problem, but also embarrassed to ask others, and lead to the decline in academic performance and so on.

The economic pressure of college students: some students' difficulties in family life. In particular, the difficulties of family life caused by sudden changes, economic pressure is greater, more likely to cause psychological crisis.

Graduates job hunting anxiety: do not have a clear understanding of their own, because they do not understand their own advantages, it is easy to lack self-confidence, feel that their future is very confused, there is no way out.

\section{The Superiority of the Instructors in the Intervention of Psychological Crisis.}

Counselors have a unique advantage in the psychological crisis intervention of College students.

The Relationship Advantage. The students packed up and entered the university campus, the 
first contact is counselor. Students follow the arrangement of counselors in all aspects of life. And counselors have more opportunities to get along with the students. The instructor's age, values, lifestyle and other aspects are similar to the students. It is easy to communicate and exchange. In the process of communication between instructors and students. It is easy to establish a good relationship between teachers and students, and gradually developed into the most trusted friend. When students leave their home, counselors become students in the hearts of relying on. When students encounter problems in life, the first time to think is to call the instructor. They are willing to share their true ideas with the instructor, the instructor can easily grasp the most realistic recent dynamic of the students. Thus, the psychological problems of students can be found in the first time.

The Advantages of Work Content. The instructor is in charge of the daily work of the students and the education management of life. Counselors can observe the students' learning situation, participate in extracurricular activities, and the relationship between teachers and students, from the details of the start, quickly understand the psychological dynamics of students. Through communicating with students, solving the psychological problems of students, and effectively avoid the generation of tragedy.

Information Superiority. The position of the instructor is special, and the first hand information of the students is mastered. Counselors through the data, test scores, family economic difficulties identification information, participating in social activities and so on ,to have a comprehensive and systematic understanding of students' personality, hobbies, habits and ability, interpersonal relationship. Counselors can conveniently obtain comprehensive information from parents, teachers, and other students in the class.

Time Advantage. Instructors generally accompany students to spend four years of College life. Such a long time to get along is more conducive to the psychological intervention of students after the follow-up. For students to maintain long-term concern, a timely understanding of the latest situation of the rehabilitation of students, is conducive to effective work is conducive to the healthy growth of students.

\section{The Way to Play the Role of Counselors in Psychological Crisis Intervention}

Psychological Intervention in the Stage of Crisis Prevention. (1) Expand their own Knowledge, and strive to improve their own Business Quality. Counselors should be through self-study, participate in the school organization psychology training, set up learning discussion groups and other ways, and strive to learn and master the knowledge of psychology, and constantly improve their professional quality. Stand in the perspective of the students, better read and find their negative emotions and incorrect their behavior, and promptly correct. Through this kind of psychological intervention to help the healthy growth of the students, to avoid a catastrophe.

(2) Should Pay Attention to the Promotion of Mental Health Knowledge. Make full use of the campus media, to carry on the extensive propaganda to the mental health knowledge. We can broadcast on campus in the campus radio station, billboards posted health education posters, can also use the WeChat campus public number, to push relevant content to the students every day.

(3) Should Pay Attention to the Education of Mental Health Knowledge. Hold a regular meeting, and we could please outside experts to carry out mental health education for students. By telling the students lively and vivid examples, to achieve the effect of psychological intervention. On the other hand, organize the students to carry on the psychological test, carry on the comprehensive analysis and evaluation, then look for the students with psychological problems to talk, help them to realize their own problems, and correct the mistakes. In addition, the school also can promote the opening of the psychological health education courses or related quality development courses.

(4) Should Make Full Use of the Strength of the Student Cadre. Student cadres are elected by vote. They are the representatives of the excellent students. They generally have relatively good popularity and affinity among the students. On the one hand, let the exemplary student cadres take the lead role, let the students to active learning from them. On the other hand, student leaders and students live together. Therefore, the student cadres can know more about what the students are 
thinking. They can find the abnormal situation of the students in a more timely manner than the counselors, and can report to the instructor in the first time. The strength of the excellent student leaders can make the psychological intervention work better. For students who need psychological help, we can carry out one to one counseling.

(5) Can Play the Role of Psychological Intervention in Extra-Curricular Activities. We can orgnize some activities. Let students learn someting as they are playing. Let the students in a relaxed and happy atmosphere, to shape a healthy mind. This way is easy to be accepted by students. At the same time, it also enriched the students' life, so that students in a place away from home to feel the warmth of the collective, feel the strength of unity and love, so as to reduce the probability of unhealthy psychological.

(6) Take a Variety of Measures at the Same Time. Strengthen the daily contact with teachers, parents and professional psychological teachers; so that you can more effectively deal with in the event of a crisis.

Psychological Intervention in the Stage of Crisis Management. The purpose of psychological crisis intervention is to provide support and assistance to students in a timely manner to find personal crisis, difficulties or setbacks, and to provide support and assistance to students. Psychological intervention process should be:

(1) Calm Down and Control the Situation. The instructor should be in the first time to the scene of the accident, to keep calm, to find out the cause of the matter as soon as possible, to maintain the scene order, to ensure the safety of students, and timely reporting. For students in real-time monitoring, to stabilize the student's mood, according to the degree of psychological crisis, to take appropriate measures, while informing the students to communicate with parents to school.

(2) Pay Attention to Communication Skills, Stable Crisis Victims. After the situation is stable, the instructor can talk with the students, in order to stabilize his bad mood, waiting for the arrival of professionals. Talking, Attitude should be sincere, the tone should be gentle, pay attention to the use of eye gaze and gestures appropriate. To stand in the perspective of the students themselves, for the sake of the students. Through this conversation, express concern and understanding to the students. Establish trust relationship with students. Make efforts to make the students as a close friend.In order to understand the student's most true ideological trends, and to provide reference for the psychological crisis intervention mechanism to determine the intervention strategy. In this way, guide students to correctly understand the crisis, so that the problem can be solved.

(3) When Necessary, Contact the Mental Health Center. If the student's psychological problems are more serious, it should be transferred to the mental health center or mental health institution in time, and all the information will be provided to the professionals. (In the stage of crisis management, the instructor must first clear their own roles and positioning. The crisis intervention is very professional. A counselor is a crisis assistance processor, not a professional crisis intervenor.)

Psychological Intervention in the Follow-up Period after the Crisis. In the post crisis period, counselors can not be relaxed, should continue to follow the students' education, timely discovery and as far as possible to avoid crisis sequelae, ensure the healthy development of students.

(1) Tracking Party. Help the parties to solve the problems left over from the crisis. And to minimize the negative impact of the incident to its. Talk with the parties, to understand their true thoughts, and be his intimate friend. Understand the concerns of the parties, and to enlighten and dredge, help them to open the heart, out of the shadow of the event. Do a good job of psychological dredging, and encourage him to take the initiative to participate in interpersonal communication, and actively participate in extra-curricular cultural activities. Let them get into the group of students as soon as possible.

(2) Guide the Students. Help students to improve their psychological quality, such as: compressive capacity, anti frustration ability, etc.. Church students, how to release the pressure, if again encountered similar things should be how to correctly face, etc.. Help their psychological growth.

(3) Sign a Letter of Commitment with the Students. Let him take the medicine on time, ensure 
the regular reexamination. If there is a psychological discomfort again, should take the initiative to the relatives and friends, professionals or counselors to seek help.

(4) Maintain Long-term Concern. In depth understanding of the students' ideological trends, talk with them, and communicate with their parents on the relevant circumstances, to jointly explore and develop appropriate follow-up measures. If necessary, we can suspend the schooling without losing his status as a student. Continue to learn after rehabilitation.

(5) Psychological Intervention for People who know about This Thing. Can carry on the collective psychological guidance. Allow students to express their sadness, guilt, fear and other emotions, to help them recover as soon as possible psychological balance, and strive to reduce the impact of the crisis.

(6) Record the Incident. Reflect on the incident, keep in the archives finally.

\section{Conclusion}

To successfully solve the psychological crisis, ultimately depends on the students to open their mind, out of the haze of the crisis, restore normal life. Instructors play a crucial role in this process. Psychological crisis prevention, the key is to discover the traces. Point out the mistakes and correct them. This paper discusses some ways of Counselor's psychological intervention, hope that through these means for the healthy growth of college students escort.

\section{Acknowledgements}

Project:Students work research branch of China's higher education institute "in 2016 university students work study general subjects: higher school counselor team construction of specialized research" (project approval number: LX2016Y013)

\section{References}

[1] Liu Jin, Probe into the way of College Students' psychological crisis intervention.

[2] Cheng Min, A study on the strategies of College Counselors' participation in psychological crisis intervention of College Students.

[3] Yang Jing, Analysis and Research on the current situation of College Students' psychological crisis intervention.

[4] Liu Yun, College counselors to play the role of psychological crisis intervention of College Students.

[5] Yang Jing, Difficulties and Countermeasures of College Students' psychological crisis intervention.

[6] Zhao Xiao, How to play the role of College Counselors in psychological crisis intervention.

[7] Shen Wenqing, Role orientation of College Counselors in psychological crisis intervention.

[8] Song Qinghua, On the role of counselors in the psychological crisis intervention of College Students.

[9] Liu Yun, On the importance of College Counselors in psychological crisis intervention.

[10]Zhan Shihuan, How to play the role of counselors in the psychological crisis intervention. 